\title{
Henoch-Schönlein Purpura
}

National Cancer Institute

\section{Source}

National Cancer Institute. Henoch-Schönlein Purpura. NCI Thesaurus. Code C34963.

A systemic, usually self-limited immune complex vasculitis, characterized by immunoglobulin A deposition in the small vessels and kidneys. It is manifested with small hemorrhages in the skin, gastrointestinal symptoms, arthritis, and nephropathy. 